\title{
Primary hydatid cyst of thigh: a rare case report
}

\author{
Agrawal S. ${ }^{1}$, Sharda P. ${ }^{2 *}$, Gupta G. ${ }^{3}$, Gupta S. ${ }^{4}$, Kundal A. ${ }^{5}$ \\ DOI: https://doi.org/10.17511/ijpr.2020.i01.07
}

\footnotetext{
1 Sonam Agrawal, Senior Resident, Department of Pediatrics, All India Institute of Medical Science, Rishikesh, Uttarakhand, India.

2* Prateek Sharda, Assistant Professor, Department of General Surgery, All India Institute of Medical Science, Rishikesh, Uttarakhand, India.

3 Gaurav Gupta, Department of General Surgery, All India Institute of Medical Science, Gorakhpur, Uttar Pradesh, India.

4 Sangeeta Gupta, Department of Physiology, All India Institute of Medical Science, Gorakhpur, Uttar Pradesh, India.

5 Ashikesh Kundal, Department of General Surgery, All India Institute of Medical Science, Gorakhpur, Uttar Pradesh, India.
}

Primary hydatid cyst elsewhere in the body is rare, as these cysts are always secondary to a hydatid of the liver or lungs. We report a case of 14-year-old girl presented with a swelling on medial aspect of left upper thigh which was gradually increasing in size since last 12 months. Ultrasonography diagnosed it as hydatid cyst, there was no swelling in the liver, lungs or elsewhere in the body, CT scan further reinforced the diagnosis. The swelling was removed en bloc and albendazole was given.

Keywords: Primary Hydatid cyst, Daughter cyst, Albendazole, Echinococcus

Corresponding Author

Prateek Sharda, Assistant Professor, Department of General Surgery, All India Institute of Medical Science, Rishikesh, Uttarakhand, India. Email: prateeksharda2006@gmail.com
How to Cite this Article

To Browse

Agrawal S, Sharda P, Gupta G, Gupta S, Kundal A. Primary hydatid cyst of thigh: a rare case report. Pediatric Rev Int J Pediatr Res. 2020;7(1):39-41. Available From

https://pediatrics.medresearch.in/index.php/ijpr/arti cle/view/571

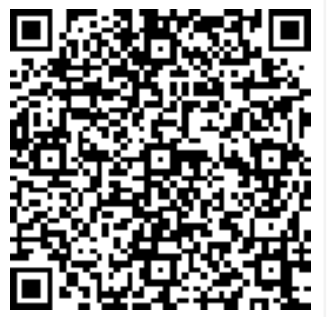

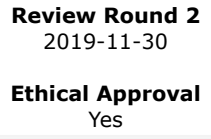

Accepted 2020-12-05

Note 


\section{Introduction}

A hydatid cyst is a parasitic disease caused by the larval form of Echinococcus granulosus or rarely Echinococcus multilocularis. The main hosts for $E$. granulosus are predators such as dogs, wolves and foxes, while intermediate hosts include sheep, goats and cattle. Humans are incidental or intermediate hosts. The organs affected most often are the liver (70\%) and lungs (10-15\%) [1]. Differential diagnosis of hydatid disease should be considered for every soft cystic mass in any anatomical location, especially in areas where the disease is endemic. In this report, we present a rare case of primary hydatid cyst located subcutaneously in the medial aspect of left upper thigh.

\section{Case Report}

A $14 y / F$ presented with a painless, gradually increasing swelling in the left upper thigh from past 12 months approximately $18 \times 15 \mathrm{~cm}$ in size. The swelling was non tender, mobile and superficial to the muscular plane in the medial aspect of upper thigh. Ultrasonography revealed a cystic swelling suggestive of hydatid cyst as daughter cysts were visible diagnostic of the disease. History of presence of a pet dog in the house was positive. CT scan was done for clear identification of the vessels, muscles and other involved structures for surgical planning (Figs. 1).

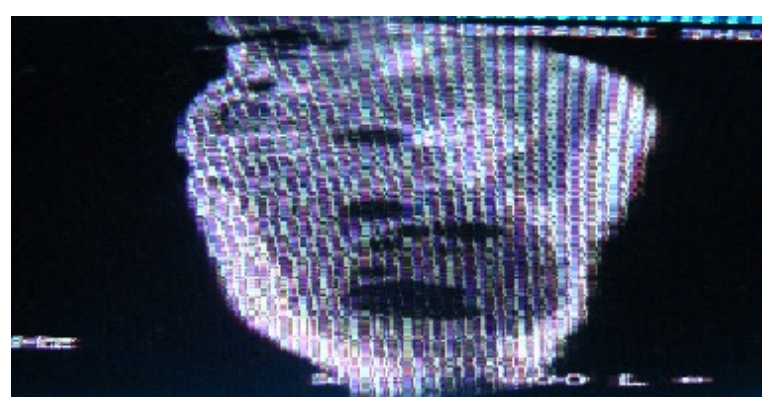

Fig.1- CT Scan showing hydatid cyst in thigh with daughter cysts.

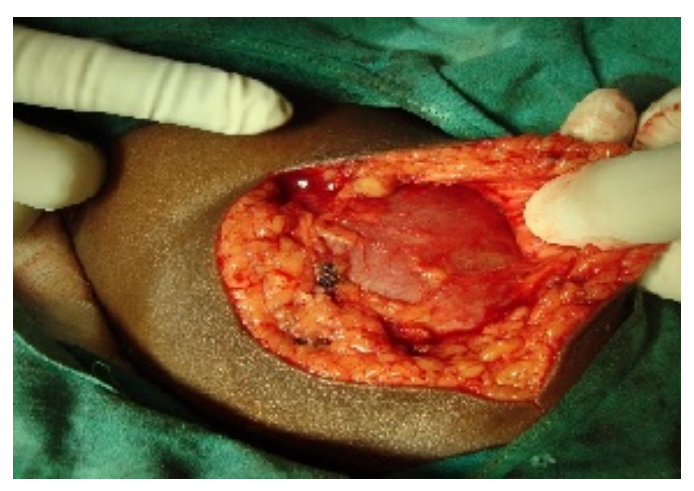

Fig-2: Intraoperative photograph showing hydatid cyst in the medial compartment of thigh.

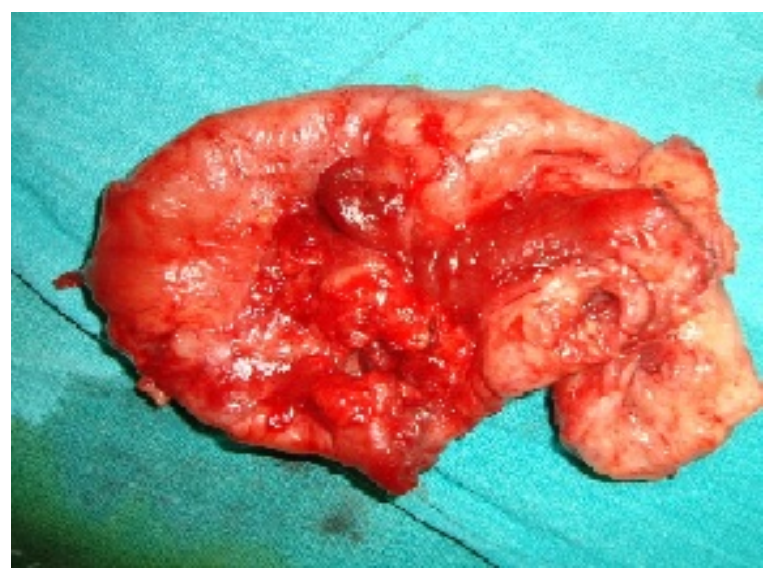

Fig-3 Intraoperative photograph showing the resected cyst(b).

Ultrasound abdomen, thorax and X-ray chest did not reveal hydatid disease of any other viscera. Cyst was removed en bloc, which was $20 \mathrm{~cm} \times 18 \mathrm{~cm}$ in dimension (Figure 2 and 3 ). Specimen was sent for Histopathological examination which confirmed it to be hydatid cyst. Patient is doing well over a follow up period of 8 months. There is no evidence of any new swelling.

\section{Discussion}

Echinococcosis is endemic in Indian subcontinent, Mediterranean countries, the Middle East, the Far East, South America, Australia, New Zealand, and East Africa. Humans contract the disease from dogs, and there is no human-to-human transmission. Musculo-skeletal hydatid disease may either be secondary or primary. In secondary disease, there is primary location of hydatid cyst in liver, lung or spleen.

The mechanism of primary subcutaneous localization is unclear. After being ingested orally, under the action of gastric and intestinal enzymes, the oncosphere is released; it penetrates the intestinal wall, joins the portal system and reaches the liver. If the eggs attach to the liver, a hepatic hydatid cyst is formed. Parasite eggs can pass to the systemic circulation through the liver going through inferior venacava than heart and cause disease in other end organs like muscles, skin etc. Larvae must pass through two filters (liver and lung) to form a solitary hydatid cyst, which is rare [2]. 
It is possible that systemic dissemination via the lymphatic route accounts for cases with solitary cysts in uncommon sites [3]. The high lactic acid level in muscle tissue is considered unfavorable for the survival of parasite [4]. Though the muscle environment is not favorable for hydatid cysts the volume of the muscle mass and its excessive blood supply could explain the rare localization in the proximal muscles of the lower limbs [5]. It has also been hypothesized that the reason for rarity of primary muscle localization could be due to bypassing through precapillary anastomosis (between pre- and postparenchyma circulation) in liver.

Direct spread from adjacent sites may be another mechanism of infection provided a micro rupture has occurred $[6,7]$. Before surgical excision or biopsy or FNAC of a swelling, diagnosis of hydatid disease should be excluded, so as to avoid leakage of cyst contents and accompanying risk of anaphylaxis and secondary hydatidosis. Ultrasonography should be performed before any invasive procedure. Ultrasound, CT scan and MRI are used preoperatively to diagnose the hydatid disease $[5,7,8]$.

Therefore, the most important diagnostic tool is the awareness of the pediatrician, particularly in the endemic areas. Surgery is definitive treatment and En bloc resection alone is curative for intramuscular hydatid disease. In this patient surgeons were able to remove whole of the cyst. Adjuvant chemotherapy was given to eliminate any possible larvae dissemination and to take care of possible hydatid disease at other sites.

\section{Conclusion}

Hydatid cyst should be considered in the differential diagnosis of subcutaneous cysts in regions where hydatid cysts are endemic. Total excision of the cyst with an intact wall is the best treatment.

\section{Reference}

01. Kayaalp C. Hydatid cyst of the liver, In Surgery of the Liver, Biliary Tract, and Pancreas 4th edition, Edited by- Blumgart LH, Belghiti RJ, DeMatteo RP, Chapman WC, Büchler MW, Hann LE, D'Angleca M. Philadelphia, PA- Saunders Elsevier. 2007;952-970. [Crossref][PubMed][Google Scholar]
02. García-Alvarez F, Torcal J, Salinas JC, Navarro A, García-Alvarez I, Navarro-Zorraquino $M$, et al. Musculoskeletal hydatid disease- a report of 13 cases. Acta Orthopaedica Scandinavica. 2002;73(2)227-231. doi: 10.1080/000164702753671858 [Crossref][PubMed] [Google Scholar]

03. Engin O, Erdoğan M. Solitary subcutaneous hydatid cyst. Am J Trop Med Hyg. 2000;62(5)583584. doi: 10.4269/ajtmh.2000.62.583 [Crossref] [PubMed][Google Scholar]

04. Tatari H, Baran Ö, Göre O, Ak D, Manisalı M, Havitçıŏlu $H$. Primary intramuscular hydatidosis of supraspinatus muscle. Arch Orthop Trauma Surg. 2001;121(1-2)93-94. doi: 10.1007/PL00013775 [Crossref][PubMed][Google Scholar]

05. Mseddi M, Mtaoumi M, Dahmene J, Ben Hamida R, Siala A, Moula T, et al. Hydatid cysts in muscleseleven cases. Rev Chir Orthop Repartrice Appar Mot. 2005;91(3)267-271. doi: 10.1016/s00351040(05)84313-2 [Crossref][PubMed][Google Scholar]

06. Verasaci A, Scuderi G, Rosato A, Angio LG, Oliva $G$, Sfuncia $G$, et al. Rare localizations of echinococcosis- personal experience. ANZ J Surg. 2005;75(11)986-991. doi: 10.1111/j.14452197.2005.03588.x [Crossref][PubMed][Google Scholar]

07. Safioleas $M$, Nikiteas $N$, Stamatakos $M$, Safioleas C, Manti $\mathrm{CH}$, Revenas C, Safioleas P. Echinococcal cyst of the subcutaneous tissue- $A$ rare case report. Parasitol Int. 2008;57(2)236-238. doi: 10.1016/j.parint.2007.11.002 [Crossref][PubMed] [Google Scholar]

08. Pedrosa I, Saiz A, Arrazola J, Ferreiros J, Pedrosa CS. Hydatid disease- Radiological and pathological features and complications. Radiograp. $2000 ; 20(3) 795-817$. doi: 10.1148/radiographics.20.3.g00ma06795 [Crossref] [PubMed][Google Scholar] 